Version définitive du manuscrit publiée dans / Final version of the manuscript published in :

Ecological Modelling (2012), Vol. 226, p. 92-98, DOI: 10.1016/j.ecolmodel.2011.10.010,

Journal homepage : www.elsevier.com/locate/ecolmodel

\title{
Inferring weed spatial distribution from multi-type data
}

\section{A. Bourgeois ${ }^{1}$, S. Gaba ${ }^{2}$, N. Munier-Jolain ${ }^{2}$, B. Borgy ${ }^{2}$, P. Monestiez ${ }^{1}$, S. Soubeyrand ${ }^{1,3}$}

\begin{abstract}
An accurate weed management in a context of sustainable agriculture relies on the knowledge about spatial weed distribution within fields. To improve the representation of patchy spatial distributions of weeds, several sampling strategies are used and lead to various weed measurements (abundance, count, patch boundaries). Here, we propose a hierarchical Bayesian model which includes such multi-type data and which allows the interpolation of weed spatial distributions (using a MCMC algorithm). The weed pattern is modeled with a $\log$ Gaussian Cox process and the various weed measurements are modeled with different observation processes. The application of the method to simulated data shows the advantage of combining several types of data (instead of using only one type of data). The method is also applied to infer the weed spatial distribution for real data.
\end{abstract}

Key words. Weed mapping, weed patch, Bayesian hierarchical model, spatial interpolation, $\log$ Gaussian Cox process

\section{Introduction}

Weeds in arable fields are a potential threat for valuable crops. Indeed, weeds may affect the crop yield and the harvest quality by introduction of impurities (Sen, 1998). On the other hand, weeds may provide food and shelter for invertebrates and birds (Holmes and Froud-Williams, 2005; Meiss et al., 2010). In a context of increasing the sustainability of agro-ecosystems, this dual function of weeds needs to be optimized. At the field scale, the choice of agricultural practices for accurate weed management, in a context of herbicide use reduction, requires that we enhance our knowledge about the spatial distribution and dynamics of weed populations.

\footnotetext{
${ }^{1}$ INRA, UR546 Biostatistique et Processus Spatiaux, F-84914 Avignon, France

${ }^{2}$ INRA, UMR1210 Biologie et Gestion des Adventices, F-21065 Dijon, France

${ }^{3}$ Corresponding author: Samuel.Soubeyrand@avignon.inra.fr
} 
Version définitive du manuscrit publiée dans / Final version of the manuscript published in :

Ecological Modelling (2012), Vol. 226, p. 92-98, DOI: 10.1016/j.ecolmodel.2011.10.010,

Journal homepage : www.elsevier.com/locate/ecolmodel

One way to acquire that knowledge is to make weed maps. Most weed maps in literature were generated with kriging (Cardina et al., 1995; Heisel et al., 1996; Clay et al., 1999), even though kriging is criticized for producing weed maps with less variation in the population at short distance than is realistic (Rew et al., 2001). The map quality relies on the spatial interpolation method (Heisel et al., 1996; Dille et al., 2002; Guillot et al., 2009) and the quality of sampling (Cousens et al., 2002). Some models have been proposed to improve spatial interpolations (Brix and Møller, 2001; Brix and Chadœuf, 2002; Kruijer et al., 2007). For example, Brix and Møller (2001) proposed a space-time multitype log Gaussian Cox process which includes pairwise interaction terms allowing the modelling of aggregation at large scale and of regularity at small scale.

Although the latter models better fit the data, they are traditionally built to map weed counting data collected over fixed-size quadrats. However, some sampling strategies have been developed to deal with time consuming manual weed counting and poor representation of weed patches. For example, to evaluate the performance of integrated weed management in four cropping systems in a long term experiment, within field weed abundance was assessed by (i) counting weeds in 30 to 40 quadrats of size $0.36 \mathrm{~m}^{2}$, (ii) giving abundance notes in 30 to 100 quadrats of size $16 \mathrm{~m}^{2}$ and (iii) giving abundance notes in weed patches with boundaries determined by GPS (Chikowo et al., 2009; Munier-Jolain et al., 2004, 2008). Mapping these three types of data is challenging because of their different natures (counting versus classes) but also because they have been assessed at different scales.

In this short communication, we propose a hierarchical Bayesian model (Clark, 2005; Wikle, 2003) which takes into account the three types of weed data (i), (ii) and (iii); see also Gotway and Young (2002) for an overview of the multi-type data topic. Our contribution is in line with the articles by Brix and Møller (2001) and Brix and Chadœuf (2002) who proposed to interpolate weed counting data with Cox processes. The novelty of our approach lies in the use of three sub-models built for the three types of data. In Section 2, the hierarchical Bayesian model including the three sub models is detailed, and the estimation and interpolation method is presented. In Section 3, the method is applied to simulated and real data and some perspectives are discussed. 
Version définitive du manuscrit publiée dans / Final version of the manuscript published in :

Ecological Modelling (2012), Vol. 226, p. 92-98, DOI: 10.1016/j.ecolmodel.2011.10.010,

Journal homepage : www.elsevier.com/locate/ecolmodel

\section{Method}

\subsection{Hierarchical Bayesian model}

In what follows, we set the point pattern model used to describe weed locations in a field. Then, we model the three types of data conditionally on the point pattern model and propose prior distributions for the model parameters. The direct acyclic graph in Figure 1 illustrates the structure of the model.

Weed locations. Let $\Omega \subset \mathbb{R}^{2}$ be the domain under study, typically a field plot. We assume that weed locations form over $\Omega$ a log Gaussian Cox process (Møller et al., 1998). The log Gaussian Cox process is a doubly stochastic point process (Diggle, 2003; Illian et al., 2008; Stoyan et al., 1995) with intensity $\lambda$ modeled as a log-normal random field. In the following, the weed intensity function $\lambda$ satisfies:

$$
\lambda(x)=\exp (\beta+S(x))
$$

where $\beta \in \mathbb{R}, S$ is a Gaussian random field with stationary exponential spatial covariance function: $C\left(x, x^{\prime}\right)=\sigma^{2} \exp \left(-\alpha\left\|x-x^{\prime}\right\|\right),\|\cdot\|$ is the Euclidean distance, $\sigma$ and $\alpha$ are in $\mathbb{R}_{+}^{*}$. If spatial explanatory variables are available (it was not the case in our data set), they may be added to $\beta+S(x)$ like in Diggle et al. (1998).

Counting data. The first type of data is the counting of weeds over disjoint quadrats $A_{1}, \ldots, A_{I}, I \in \mathbb{N}$, included in $\Omega$. Let $Y_{i}$ be the count of weeds in quadrat $A_{i}$. Under the process for weed locations defined above, $Y_{i}$ given $\lambda$ follows a Poisson distribution with mean $\Lambda\left(A_{i}\right)=\int_{A_{i}} \lambda(x) d x$ and for all $i \in\{1, \ldots, I\}$

$$
\mathbb{P}\left(Y_{i}=n \mid \lambda\right)=e^{-\Lambda\left(A_{i}\right)} \frac{\Lambda\left(A_{i}\right)^{n}}{n !}, \quad \forall n \in \mathbb{N}
$$

Abundance data. The second type of data is the assessment of the quantity of weeds over disjoint quadrats $A_{I+1}, \ldots, A_{I+J}$ included in $\Omega, J \in \mathbb{N}$, using a simplified version of the Barralis scale (Barralis, 1976; Munier-Jolain, 2010). For $i \in\{I+1, \ldots, I+J\}$, if the number of weeds $Y_{i}$ in $A_{i}$ is low, i.e. less than or equal to $n_{1}$, then this number is observed; if the number of weeds is high, i.e. greater than $n_{1}$, then $Y_{i}$ is censored in the $Q$ intervals 
Version définitive du manuscrit publiée dans / Final version of the manuscript published in :

Ecological Modelling (2012), Vol. 226, p. 92-98, DOI: 10.1016/j.ecolmodel.2011.10.010,

Journal homepage : www.elsevier.com/locate/ecolmodel

$\left(n_{1}, n_{2}\right], \ldots,\left(n_{Q-1}, n_{Q}\right],\left(n_{Q}, n_{Q+1}=\infty\right)$. Values of $n_{1}, \ldots, n_{Q+1}$ for the applications are provided in Appendix A. Under the process for weed locations defined above, $Y_{i}$ given $\lambda$ is Poisson distributed with mean $\Lambda\left(A_{i}\right)=\int_{A_{i}} \lambda(x) d x$ (as above) and for all $i \in\{I+1, \ldots, I+J\}$

$$
\begin{gathered}
\mathbb{P}\left(Y_{i}=n \mid \lambda\right)=e^{-\Lambda\left(A_{i}\right)} \frac{\Lambda\left(A_{i}\right)^{n}}{n !}, \quad \forall n \in\left\{0,1, \ldots, n_{1}\right\}, \\
\mathbb{P}\left(Y_{i} \in\left(n_{q}, n_{q+1}\right] \mid \lambda\right)=\sum_{n=n_{q}+1}^{n_{q+1}} e^{-\Lambda\left(A_{i}\right)} \frac{\Lambda\left(A_{i}\right)^{n}}{n !}, \quad \forall q \in\{1,2, \ldots, Q\} .
\end{gathered}
$$

Patch data. The third type of data is the counting of weeds over patches $A_{I+J+1}, \ldots, A_{I+J+K}$ included in $\Omega, K \in \mathbb{N}$, with high weed densities with respect to the surroundings of these patches. The surroundings are denoted by $\tilde{A}_{I+J+1}, \ldots, \tilde{A}_{I+J+K}$. For $i \in\{I+J+1, \ldots, I+$ $J+K\}$, the number of weeds per area unit in patch $A_{i}$ is assumed to be $\gamma$ times higher than the number of weeds per unit area in the patch surrounding $\tilde{A}_{i}(\gamma \geq 1)$. Under the process for weed locations defined above, for all $i \in\{I+J+1, \ldots, I+J+K\}, Y_{i}$ given $\lambda$ is Poisson distributed with mean $\Lambda\left(A_{i}\right)=\int_{A_{i}} \lambda(x) d x$ (as above) and $Y_{i} /\left|A_{i}\right| \geq \gamma \tilde{Y}_{i} /\left|\tilde{A}_{i}\right| ;\left|A_{i}\right|$ and $\left|\tilde{A}_{i}\right|$ are the areas of $A_{i}$ and $\tilde{A}_{i}$. Consequently, for all $i \in\{I+J+1, \ldots, I+J+K\}$ and $n \in \mathbb{N}$,

$$
\begin{aligned}
\mathbb{P}\left(Y_{i}=n, Y_{i} /\left|A_{i}\right| \geq \gamma \tilde{Y}_{i} /\left|\tilde{A}_{i}\right| \mid \lambda\right) & =\mathbb{P}\left(\tilde{Y}_{i} \leq Y_{i}\left|\tilde{A}_{i}\right| / \gamma\left|A_{i}\right| \mid Y_{i}=n, \lambda\right) \mathbb{P}\left(Y_{i}=n \mid \lambda\right) \\
& =\left(\sum_{n^{\prime}=0}^{\left\lfloor n\left|\tilde{A}_{i}\right| / \gamma\left|A_{i}\right|\right\rfloor} \mathbb{P}\left(\tilde{Y}_{i}=n^{\prime} \mid \lambda\right)\right) \mathbb{P}\left(Y_{i}=n \mid \lambda\right) \\
& =\left(\sum_{n^{\prime}=0}^{\left\lfloor n\left|\tilde{A}_{i}\right| / \gamma\left|A_{i}\right|\right\rfloor} e^{-\Lambda\left(\tilde{A}_{i}\right)} \frac{\Lambda\left(\tilde{A}_{i}\right)^{n^{\prime}}}{n^{\prime} !}\right) e^{-\Lambda\left(A_{i}\right)} \frac{\Lambda\left(A_{i}\right)^{n}}{n !}
\end{aligned}
$$

where $\left\lfloor n\left|\tilde{A}_{i}\right| / \gamma\left|A_{i}\right|\right\rfloor$ is the floor value of $n\left|\tilde{A}_{i}\right| / \gamma\left|A_{i}\right|$.

Prior distributions for the parameters. In this article, the parameter $\gamma$ is assumed to be equal to one. This is the most conservative value for $\gamma$ when no additional information is available; the specification of $\gamma$ is discussed in Section 3. For $\beta, \log \sigma$ and $\log \alpha$, we assumed independent centered normal prior distributions with variances $\tau_{\beta}^{2}, \tau_{\sigma^{2}}^{2}$ and $\tau_{\alpha}^{2}$ equal to $100^{2}$. Vague priors were used because no information was available on the parameters. Thus, hierarchical Bayesian modeling is not invoked to include expert information but to exploit MCMC which allows us to provide a posterior distribution for the weed intensity function. 
Version définitive du manuscrit publiée dans / Final version of the manuscript published in :

Ecological Modelling (2012), Vol. 226, p. 92-98, DOI: 10.1016/j.ecolmodel.2011.10.010,

Journal homepage : www.elsevier.com/locate/ecolmodel

\subsection{Estimation and interpolation}

Assuming that the contours of the sampling units (i.e. the quadrats, the patches and the patch surroundings) are known, the hierarchical model presented above may be used to write a posterior distribution allowing the interpolation of the weed intensity function.

Posterior distribution. Let $\mathbf{Y}$ denote the set of counting, abundance and patch data. From the dependence structure provided by Figure 1, the joint posterior distribution of the unknowns (weed intensity function and parameters) is proportional to

$$
\begin{aligned}
p(\lambda, \beta, \sigma, \alpha \mid \mathbf{Y}) & \propto p(\mathbf{Y}, \lambda \mid \beta, \sigma, \alpha) \pi(\beta, \sigma, \alpha) \\
& =p(\mathbf{Y} \mid \lambda) p(\lambda \mid \beta, \sigma, \alpha) \pi(\beta, \sigma, \alpha) \\
& =p(\mathbf{Y} \mid \lambda) \mathbf{1}\{\lambda \equiv \exp (\beta+S)\} p(S \mid \sigma, \alpha) \pi(\beta, \sigma, \alpha) .
\end{aligned}
$$

where $p(\mathbf{Y}, \lambda \mid \beta, \sigma, \alpha)$ is the complete likelihood of the model; $\pi$ is the joint prior distribution of the parameters, i.e. a product of normal densities; $p(\mathbf{Y} \mid \lambda)$ is the conditional distribution of the data given $\lambda ; p(\lambda \mid \beta, \sigma, \alpha)$ is the distribution of $\lambda$ which can be written as the product of the indicator function $\mathbf{1}\{\lambda \equiv \exp (\beta+S)\}$ — which equals one if $\lambda$ coincides with $\exp (\beta+S)$ and the distribution $p(S \mid \sigma, \alpha)$ of the Gaussian random field $S$. The indicator function appears because of the deterministic link between $\lambda, \beta$ and $S$.

Conditional distribution $p(\mathbf{Y} \mid \lambda)$. Regarding the $J$ abundance data, we suppose that there are $J_{1}$ observed counts, where $0 \leq J_{1} \leq J$, and $J-J_{1}$ counts censored in intervals. Then, $\mathbf{Y}$ can be written as follows:

$$
\mathbf{Y}=\left\{y_{1}, \ldots, y_{I+J_{1}},\left[\underline{y}_{I+J_{1}+1}, \bar{y}_{I+J_{1}+1}\right], \ldots,\left[\underline{y}_{I+J}, \bar{y}_{I+J}\right], y_{I+J+1}, \ldots, y_{I+J+K}\right\},
$$

where the symbols $y_{i}$ denote the observed counts and the symbols $\underline{y}_{i}$ and $\bar{y}_{i}$ denote the lower and upper bounds of the intervals in which some of the observed counts are censored. Given the contours of the sampling units, the distribution $p(\mathbf{Y} \mid \lambda)$ can be written, if $J_{1}<J$ :

$$
\begin{aligned}
p(\mathbf{Y} \mid \lambda)= & \left(\prod_{\substack{i \in\left\{1, \ldots, I+J_{1}\right\} \bigcup \\
\{I+J+1, \ldots, I+J+K\}}} e^{-\Lambda\left(A_{i}\right)} \frac{\Lambda\left(A_{i}\right)^{y_{i}}}{y_{i} !}\right) \times \prod_{i=I+J_{1}+1}^{I+J}\left(\sum_{y=\underline{y}_{i}} e^{-\Lambda\left(A_{i}\right)} \frac{\Lambda\left(A_{i}\right)^{y}}{y !}\right) \\
& \times \prod_{i=I+J+1}^{\substack{I+J+K}}\left(\sum_{y=0}^{\left.\left\lfloor y_{i}\left|\tilde{A}_{i}\right| / \gamma \mid A_{i}\right\rfloor\right\rfloor} e^{-\Lambda\left(\tilde{A}_{i}\right)} \frac{\Lambda\left(\tilde{A}_{i}\right)^{y}}{y !}\right) .
\end{aligned}
$$


Version définitive du manuscrit publiée dans / Final version of the manuscript published in :

Ecological Modelling (2012), Vol. 226, p. 92-98, DOI: 10.1016/j.ecolmodel.2011.10.010,

Journal homepage : www.elsevier.com/locate/ecolmodel

If $J_{1}=J$ (no count censored in interval), then the second product in Eq. (3) has to be deleted.

Some of the sampling units may overlap (in the real data, there are 12 overlaps for 135 sampling units). For such overlapping sampling units, the corresponding weed measures are dependent conditional on $\lambda$. This dependence is ignored in Eq. (3); an approach to take it into account is discussed in Section 3.

Integral approximation and distribution $p(S \mid \sigma, \alpha)$. The weed intensity function $\lambda$ being the function to be estimated, the integrals $\Lambda\left(A_{i}\right), i=1, \ldots, I+J+K$, and $\Lambda\left(\tilde{A}_{i}\right)$, $i=I+J+1, \ldots, I+J+K$, are unknown. These integrals are approximated as follows: let $\lambda\left(x_{1}\right), \ldots, \lambda\left(x_{M}\right)$ denote the values of $\lambda$ in a finite number of points $x_{1}, \ldots, x_{M}$ included in the sampling units; let $A$ denote any sampling unit; the approximation of $\Lambda(A)$ is

$$
\check{\Lambda}_{M}(A)=\frac{|A|}{\sum_{m=1}^{M} \mathbf{1}\left(x_{m} \in A\right)} \sum_{m=1}^{M} \lambda\left(x_{m}\right) \mathbf{1}\left(x_{m} \in A\right) \approx \Lambda(A),
$$

where $\mathbf{1}(\cdot)$ is the indicator function.

In the estimation algorithm, the approximation $\check{\Lambda}_{M}$ replaces the function $\Lambda$ in Eq. (3). It follows that the distribution $p(S \mid \sigma, \alpha)$ in Eq. (1) reduces to the distribution of the spatial Gaussian vector $S\left(x_{1}\right), \ldots, S\left(x_{M}\right)$; the expression of this distribution is given in Stein (1999, Appendix A).

In the estimation algorithm, the values of $S\left(x_{1}\right), \ldots, S\left(x_{M}\right)$ are updated at each iteration. Thus, for large $M$ the algorithm may be very time consuming (e.g. for the real data, we set $M=152$ and it took about 40 hours to run $10^{5} \mathrm{MCMC}$-iterations with an up-to-date computer and the $\mathrm{R}$ software).

MCMC algorithm. Our model with various observation processes is an extension of spatial generalized linear mixed models used in model-based geostatistics (Diggle et al., 1998). Thus, we adapted the MCMC algorithm presented by Diggle et al. (1998) to (i) estimate $\lambda\left(x_{1}\right), \ldots, \lambda\left(x_{M}\right)$ and (ii) interpolate $\lambda$ at the nodes of a grid covering the study domain $\Omega$. The main adaptation deals with the expression of the likelihood (see above). Information about the starting values and the proposal distributions are provided in Appendix A. 
Version définitive du manuscrit publiée dans / Final version of the manuscript published in :

Ecological Modelling (2012), Vol. 226, p. 92-98, DOI: 10.1016/j.ecolmodel.2011.10.010,

Journal homepage : www.elsevier.com/locate/ecolmodel

\section{Results and discussion}

We applied the method proposed above to a simulated data set and a real one (available at http://samuel.biosp.org). The corresponding weed measurements are shown on Figure 2.

Simulated data. The simulated data set was generated under the hierarchical model of Section 2.1 with $\left(\beta, \sigma^{2}, \alpha\right)=(0.5,2,1 / 35), \Omega=[0,152] \times[0,152]$. The true weed intensity function $\lambda$ and the collected data are shown on the left panel of Figure 2. There are $I+J+2 K=$ $50+100+2 \times 3=156$ sampling units ( 2 times $K$ because there are $K$ patches and $K$ patch surroundings); there are seven pairs of overlapping sampling units. For the integral approximation in the estimation algorithm, we set $M=158$ points distributed in the 156 sampling units. We used only one point per quadrat because each quadrat area was less than $0.07 \%$ of the total area of $\Omega$. For the patches and patch surroundings we used numbers of points proportional to their areas. For the distribution of the number of weeds in the patch surroundings, we used $\gamma=1$.

The interpolated posterior median of $\lambda$ and the posterior quantiles of order 0.005 and 0.995 are displayed on Figure 3 (second line). We also drawn the analogue maps obtained when only the abundance data are used (third line). Visually, the true weed intensity function $\lambda$ (top left panel of Figure 3) is correctly interpolated by its posterior distribution obtained with all the data. $85.9 \%$ of the true values of $\lambda$ are in the corresponding marginal 99\%-posterior intervals; see Table 1. This percentage is lower than expected but will increase with the quantity of information brought by the data. Besides, despite the partial inadequacy between the true $\lambda$ and its estimation, $99.4 \%$ of the observations are correctly predicted by the posterior model; see Table 1 . When only the abundance data are used, the interpolation is poorer; see Figure 3 (third line) and Table 1. This illustrates the advantage of combining the three types of data.

Real data. The real data set concerns the cleavers sampled in May 2006 in a wheat field located near Dijon, France. There are $I+J+2 K=30+91+2 \times 7=135$ sampling units; there are twelve pairs of overlapping sampling units. For the integral approximation in the estimation algorithm, we set $M=152$ points distributed in the 135 sampling units. For the distribution of the number of weeds in the patch surroundings, we used $\gamma=1$. 
Version définitive du manuscrit publiée dans / Final version of the manuscript published in :

Ecological Modelling (2012), Vol. 226, p. 92-98, DOI: 10.1016/j.ecolmodel.2011.10.010,

Journal homepage : www.elsevier.com/locate/ecolmodel

The interpolated posterior median of $\lambda$ and the posterior quantiles of order 0.005 and 0.995 are displayed on Figure 4. 100\% of the observations are covered by their marginal 99\%-posterior intervals (PI) obtained by simulation under the posterior distributions of the unknowns; The legend of Table 1 explains how this coverage is computed. Moreover, we carried out a posterior predictive assessment of the model fitness by applying the approach of Gelman et al. (1996). The posterior predictive $p$-value which equals 0.51 supports the adequacy of the fitted model to the real data; see Appendix A for details about the test.

Such interpolations could be used to study the spatio-temporal dynamics of weeds and the interaction between different weed species.

Methodological perspectives. With the method presented above we progressed in the mapping of the weed spatial distribution in a field because we are able to include in the interpolation several types of data. However, some points may be improved to obtain a more accurate inference. Indeed, it should be possible to take into account:

- the uncertainty of contours for large quadrats, patches and surrounding patches;

- the uncertainty in the intervals in which the counts are censored for abundance data and the uncertainty in the counts for patch data, because these observations are only based on visual assessment in the real data;

- the dependence of observations made for overlapping sampling units. It could be easy to take into account this dependence for quadrats included in larger sampling units (differences between two counts or a count and an interval). However, taking into account this dependence for partially overlapping sampling units is not obvious.

Improving our method in these directions could be possible by including supplementary latent variables in the model, but this solution may lead to very time-consuming algorithms.

Another improvement could be the assessment of the parameter $\gamma$ which governs the distribution of the number of weeds in the patch surroundings. In theory, this parameter could be estimated with the MCMC algorithm. Counting and abundance data collected within the patch surroundings would help the MCMC to provide a posterior distribution for $\gamma$. However, in the data set analyzed in this article, the number of such data was too low. Thus, we preferred to use the conservative value $\gamma=1 . \gamma=1$ implies that the density of weeds within the patch (DWP) 
Version définitive du manuscrit publiée dans / Final version of the manuscript published in :

Ecological Modelling (2012), Vol. 226, p. 92-98, DOI: 10.1016/j.ecolmodel.2011.10.010,

Journal homepage : www.elsevier.com/locate/ecolmodel

is only greater than or equal to the density of weeds within the patch surrounding (DWPS). $\gamma>1$ would imply that DWP is greater than DWPS. In the interpolation of the weed intensity function, $\gamma>>1$ would make appear rings of very low intensity around the patches.

From kriging to model-based geostatistics. We mentioned in the introduction that kriging is often applied to interpolate weed spatial distributions. However, with multitype data and heterogeneous sampling units, regular kriging cannot be directly applied. One must first transform the data and discard those which cannot be transformed correctly. For instance, we should have to homogenize supports and distributions of counting, abundance and patch data, and discard patch surrounding data to be able to apply indicator kriging, ordinary kriging (Chilès and Delfiner, 1999) or Poisson kriging (Monestiez et al., 2006). Since the article by Diggle et al. (1998), kriging (naturally associated with Gaussian assumptions, see Diggle et al., 1998; Stein, 1999) has been extended to model-based kriging which is associated with spatial generalized linear mixed modeling. Thus, the approach proposed in this communication is in this vein and is nothing else than model-based kriging with various observation models.

Acknowledgements. The authors thank an anonymous reviewer for his suggestions as well as Edith Gabriel for her comments on an early draft of the manuscript. This work was supported by the ANR grant STRA-08-02 Advherb.

\section{References}

Barralis, G. (1976). Méthode d'étude des groupements adventices des cultures annuelles: application la Côte d'Or. Vème Colloque International d'Ecologie et de Biologie des Mauvaises Herbes, Dijon, 59-68.

Brix, A. and J. Chadouf (2002). Spatio-temporal modelling of weeds by shot-noise G Cox processes. Biometrical Journal 44, 83-99.

Brix, A. and J. Møller (2001). Space-time multi type log Gaussian Cox processes with a view to modelling weeds. Scandinavian Journal of Statistics 28, 471-488. 
Version définitive du manuscrit publiée dans / Final version of the manuscript published in :

Ecological Modelling (2012), Vol. 226, p. 92-98, DOI: 10.1016/j.ecolmodel.2011.10.010,

Journal homepage : www.elsevier.com/locate/ecolmodel

Cardina, J. D., H. Sparrow, and E. McCoy (1995). Analysis of spatial distribution of common lamsquarters chenopodium album in no-till soybean. Weed Science 44, 298-308.

Chikowo, R., V. Faloya, S. Petit, and N. Munier-Jolain (2009). Integrated weed management systems allow reduced reliance on herbicides and long-term weed control. Agriculture, Ecosystems and Environment 132, 237-242.

Chilès, J. and P. Delfiner (1999). Geostatistics: modeling spatial uncertainty, Volume 344. Wiley-Interscience.

Clark, J. S. (2005). Why environmental scientists are becoming bayesians. Ecology Letters 8, $2-14$.

Clay, S. A., G. J. Lems, D. E. Clay, F. Forcella, M. E. Ellsbury, and C. G. Carlson (1999). Analysis of spatial distribution of common lamsquarters chenopodium album in no-till soybean. Weed Science 47, 674-681.

Cousens, R., R. Brown, A. McBratney, B. Whelan, and M. Moerkerk (2002). Sampling strategy is important for producing weed maps: a case study using kriging. Weed Science 50, 542-546.

Diggle, P. J. (2003). Statistical Analysis of Spatial Point Patterns. New York: Oxford University Press.

Diggle, P. J., J. A. Tawn, and R. A. Moyeed (1998). Model-based geostatistics. Journal of the Royal Statistical Society, C 47, 299-350.

Dille, J., M. Milner, J. Groeteke, D. Mortensen, and M. Williams (2002). How good is your weed map ? a comparison of spatial interpolators. Weed Science 51, 44-55.

Gelman, A., X. Meng, and H. Stern (1996). Posterior predictive assessment of model fitness via realized discrepancies. Statistica Sinica 6, 733-759.

Gotway, C. A. and L. J. Young (2002). Combining incompatible spatial data. Journal of the American Statistical Association 97\%, 632-648. 
Version définitive du manuscrit publiée dans / Final version of the manuscript published in :

Ecological Modelling (2012), Vol. 226, p. 92-98, DOI: 10.1016/j.ecolmodel.2011.10.010,

Journal homepage : www.elsevier.com/locate/ecolmodel

Guillot, G., N. Loren, and M. Rudemo (2009). Spatial prediction of weed intensities from exact count data and image-based estimates. Journal of the Royal Statistical Society Series C-applied Statistics 58, 525-542.

Heisel, T., C. Andreasen, and A. K. Ersboll (1996). Annual weed distributions can be mapped with kriging. Weed Science 36, 325-333.

Holmes, R. J. and R. J. Froud-Williams (2005). Post-dispersal weed seed predation by avian and non-avian predators. Agriculture, Ecosystems \& Environment 105, 23-27.

Illian, J., A. Penttinen, H. Stoyan, and D. Stoyan (2008). Statistical Analysis and Modelling of Spatial Point Patterns. Wiley.

Kruijer, W., A. Stein, W. Schaafsma, and S. Heijting (2007). Analyzing spatial count data, with an application to weed counts. Environmental and Ecological Statistics 14, 399-410.

Meiss, H., L. Le Lagadec, N. Munier-Jolain, R. Waldhardt, and S. Petit (2010). Weed seed predation increases with vegetation cover in perennial forage crops. Agriculture, Ecosystems \& Environment 138, 10-16.

Møller, J., A. R. Syversveen, and R. P. Waagepetersen (1998). Log Gaussian Cox process. Scandinavian Journal of Statistics 25, 451-482.

Monestiez, P., L. Dubroca, E. Bonnin, J. Durbec, and C. Guinet (2006). Geostatistical modelling of spatial distribution of balaenoptera physalus in the northwestern mediterranean sea from sparse count data and heterogeneous observation efforts. Ecological Modelling 193(3-4), $615-628$.

Munier-Jolain, N. (2010). Rapid weed survey at the field scale. Technical report, INRA Quantipest platform.

Munier-Jolain, N., V. Deytieux, J. P. Guillemin, S. Granger, and S. Gaba (2008). Conception et évaluation multicritères de prototypes de systèmes de culture dans le cadre de la protection intégrée contre la flore adventice en grandes cultures. Innovations Agronomiques 3, 75-88. 
Version définitive du manuscrit publiée dans / Final version of the manuscript published in :

Ecological Modelling (2012), Vol. 226, p. 92-98, DOI: 10.1016/j.ecolmodel.2011.10.010,

Journal homepage : www.elsevier.com/locate/ecolmodel

Munier-Jolain, N., V. Faloya, J. B. Davaine, L. Biju-Duval, D. Meunier, C. Martin, and R. Charles (2004). A cropping system experiment for testing the principles of integrated weed management. Annales AFPP, XIIème colloque international sur la lutte contre les mauvaises herbes, Dijon, 147-156.

Rew, L. J., B. Whelan, and A. B. McBratney (2001). Does kriging predict weed distributions accurately enough for site-specific weed control? Weed Research 41, 245-263.

Sen, D. N. (1998). Key factors affecting weed-crop balance in agroecosystems. In M. A. Altieri and L. M (Eds.), Weed Management in Agroecosystems: Ecological Approaches, pp. 157-182. CRC Press, New York.

Stein, M. L. (1999). Interpolation of Spatial Data: Some Theory for Kriging. New York: Springer-Verlag.

Stoyan, D., W. S. Kendall, and J. Mecke (1995). Stochastic Geometry and its Applications, 2nd Ed. Chichester: Wiley.

Wikle, C. K. (2003). Hierarchical models in environmental science. International Statistical Review 71, 181-199.

\section{A Supplementary material}

Interval values. Regarding the abundance data in the simulated and real applications, the intervals in which the weed counts are censored are $\left(n_{1}, n_{2}\right]=(9,15],\left(n_{2}, n_{3}\right]=(15,47]$, $\left(n_{3}, n_{4}\right]=(47,319],\left(n_{4}, n_{5}\right]=(319,799],\left(n_{5}, n_{6}\right]=(799,7999],\left(n_{6}, \infty\right)=(7999, \infty)$. They correspond to a simplification of the Barralis scale (Barralis, 1976; Munier-Jolain, 2010).

MCMC tuning. The starting values of $S\left(x_{1}\right), \ldots, S\left(x_{M}\right)$ were fixed at zero and arbitrary starting values for $\beta, \sigma$ and $\alpha$ were chosen so that the initial values of the log-likelihood and the log-priors were finite. Regarding the proposal distributions, new values for $S\left(x_{1}\right), \ldots, S\left(x_{M}\right)$, $\beta, \log \sigma$ and $\log \alpha$ were proposed with univariate normal distributions centered on the current values. Block updating was used only for $\log \sigma$ and $\log \alpha$. Besides, we ran in each case (simulated 
Version définitive du manuscrit publiée dans / Final version of the manuscript published in :

Ecological Modelling (2012), Vol. 226, p. 92-98, DOI: 10.1016/j.ecolmodel.2011.10.010,

Journal homepage : www.elsevier.com/locate/ecolmodel

and real data) $10^{5} \mathrm{MCMC}$-iterations and obtained the posterior sample of $\lambda$ by sub-sampling in the chains every 10 iterations after a burnin of $10^{4}$ iterations. The interpolation of $\lambda$ was made for the 9000 iterations which were sub-sampled.

Posterior predictive assessment of the model fitness. We applied the approach of Gelman et al. (1996) by using a $\chi^{2}$-like discrepancy:

$$
\begin{aligned}
\chi^{2}\left(\mathbf{Y} ; \lambda^{(z)}\right)= & \left(\sum_{\substack{i \in\left\{1, \ldots, I+J_{1}\right\} \bigcup \\
\{I+J+1, \ldots, I+J+K\}}} \frac{\left\{y_{i}-\check{\Lambda}_{M}^{(z)}\left(A_{i}\right)\right\}^{2}}{\check{\Lambda}_{M}^{(z)}\left(A_{i}\right)}\right)+\left(\sum_{i=I+J_{1}+1}^{I+J} \frac{\left\{\frac{1}{2}\left(\bar{y}_{i}-\underline{y}_{i}\right)-\check{\Lambda}_{M}^{(z)}\left(A_{i}\right)\right\}^{2}}{\check{\Lambda}_{M}^{(z)}\left(A_{i}\right)}\right) \\
& +\left(\sum_{i=I+J+1}^{I+J+K} \frac{\left\{\left(\frac{1}{2}\left\lfloor\frac{y_{i}\left|\tilde{A}_{i}\right|}{\gamma\left|A_{i}\right|}\right\rfloor-\check{\Lambda}_{M}^{(z)}\left(A_{i}\right)\right\}^{2}\right.}{\check{\Lambda}_{M}^{(z)}\left(A_{i}\right)}\right) .
\end{aligned}
$$

where $\lambda^{(z)}$ is the state of $\lambda$ in the $z$-th iteration of the MCMC algorithm and

$$
\check{\Lambda}_{M}^{(z)}\left(A_{i}\right)=\frac{\left|A_{i}\right|}{\sum_{m=1}^{M} \mathbf{1}\left(x_{m} \in A_{i}\right)} \sum_{m=1}^{M} \lambda^{(z)}\left(x_{m}\right) \mathbf{1}\left(x_{m} \in A_{i}\right) .
$$

For the abundance data and patch surrounding data censored in intervals, we used the middles of the intervals instead of the unobserved weed counts $y_{i}$. For abundance data, the middle of the interval $\left[\underline{y}_{i}, \bar{y}_{i}\right]$ is $\frac{1}{2}\left(\bar{y}_{i}-\underline{y}_{i}\right)$; for patch surrounding data, the middle of the interval $\left[0,\left\lfloor\frac{y_{i}\left|\tilde{A}_{i}\right|}{\gamma\left|A_{i}\right|}\right\rfloor\right]$ is $\frac{1}{2}\left\lfloor\frac{y_{i}\left|\tilde{A}_{i}\right|}{\gamma\left|A_{i}\right|}\right\rfloor$.

The posterior predictive $p$-value was obtained as follows. For each $\lambda^{(z)}$ a replicated data set $\mathbf{Y}_{\text {rep }}^{(z)}$ was simulated. Then, we computed the realized discrepancy $\chi^{2}\left(\mathbf{Y} ; \lambda^{(z)}\right)$ and the predictive discrepancy $\chi^{2}\left(\mathbf{Y}_{\text {rep }}^{(z)} ; \lambda^{(z)}\right)$ for each iteration $z$ and drawn the corresponding scatterplot; see Figure 5 . The $p$-value was estimated by the proportion of points above the $45^{\circ}$ line, i.e. $p$ value $=0.51$. 
Version définitive du manuscrit publiée dans / Final version of the manuscript published in :

Ecological Modelling (2012), Vol. 226, p. 92-98, DOl: 10.1016/j.ecolmodel.2011.10.010,

Journal homepage : www.elsevier.com/locate/ecolmodel

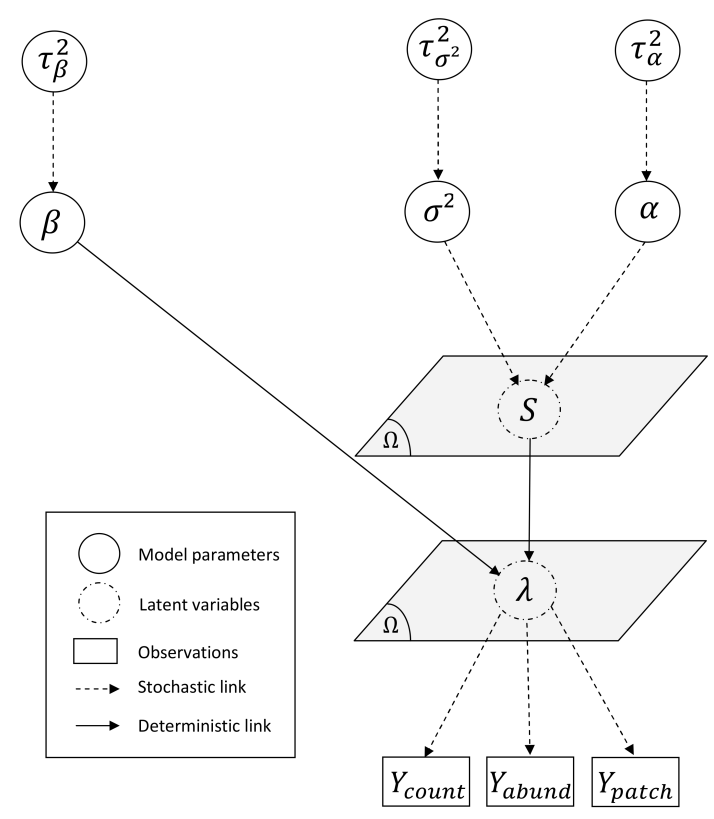

Figure 1: Direct acyclic graph showing the structure of the hierarchical Bayesian model.
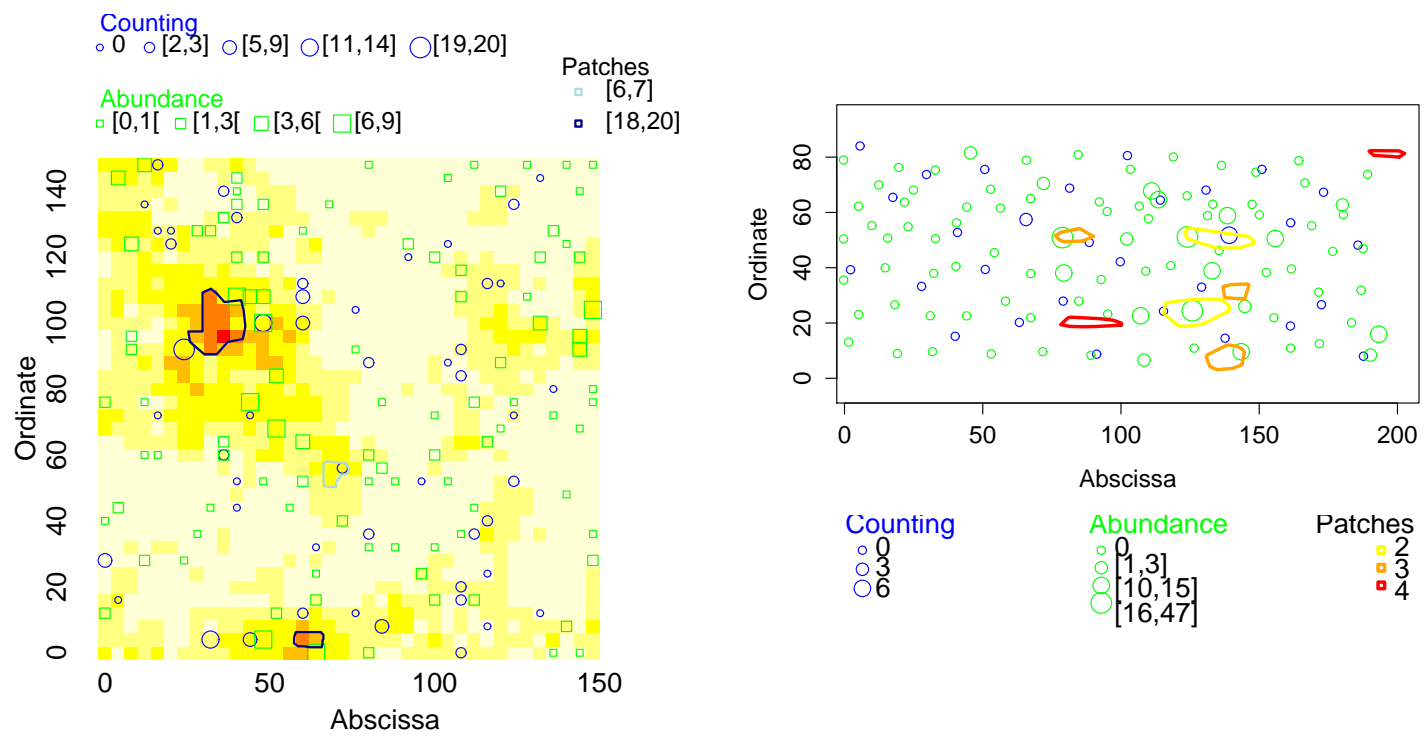

Figure 2: Simulated data set (left) and real data set (right; measures of cleavers in a wheat field in May 2006, France). For the simulated data set, the true weed intensity function $\lambda$ is shown. The intervals provided in the legends merge the counts and intervals in the data tables. 
Version définitive du manuscrit publiée dans / Final version of the manuscript published in :

Ecological Modelling (2012), Vol. 226, p. 92-98, DOl: 10.1016/j.ecolmodel.2011.10.010,

Journal homepage : www.elsevier.com/locate/ecolmodel

Table 1: Coverage statistics for the simulated data set. Coverage of the true values of $\lambda$ by their marginal 99\%-posterior intervals (PI); assessed for 1444 values of $\lambda$ at the grid nodes. Coverage of the observations by their marginal 99\%-PI obtained by simulation under the posterior distributions of the unknowns; For any observed weed count, we checked if the count was in its PI; For any count censored in an interval, we checked if this interval was intersecting the PI.

\begin{tabular}{lrr}
\hline & All data & Only abundance data \\
\hline Coverage of $\lambda$ values & $85.9 \%$ & $63.9 \%$ \\
Coverage of observations & $99.4 \%$ & $99.0 \%$ \\
\hline
\end{tabular}


Version définitive du manuscrit publiée dans / Final version of the manuscript published in :

Ecological Modelling (2012), Vol. 226, p. 92-98, DOl: 10.1016/j.ecolmodel.2011.10.010,

Journal homepage : www.elsevier.com/locate/ecolmodel
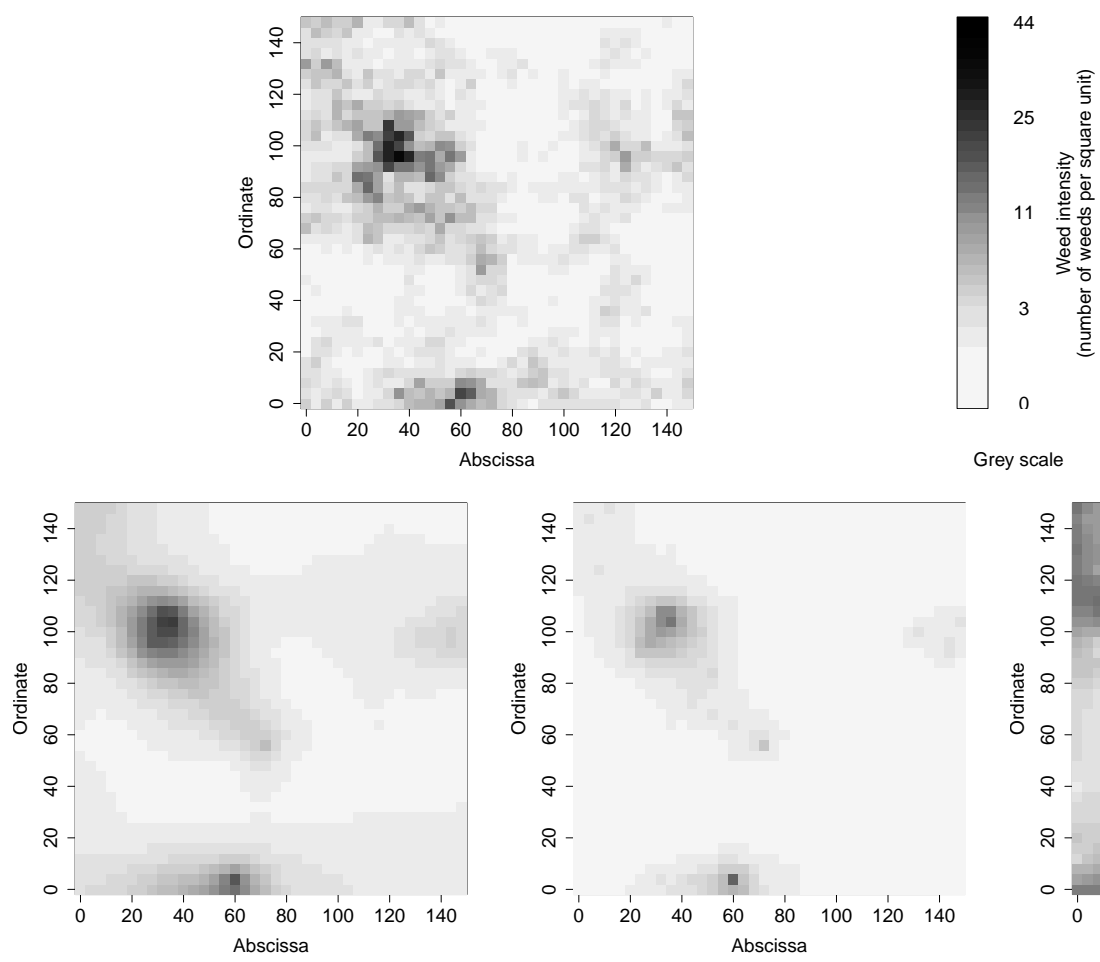

Grey scale
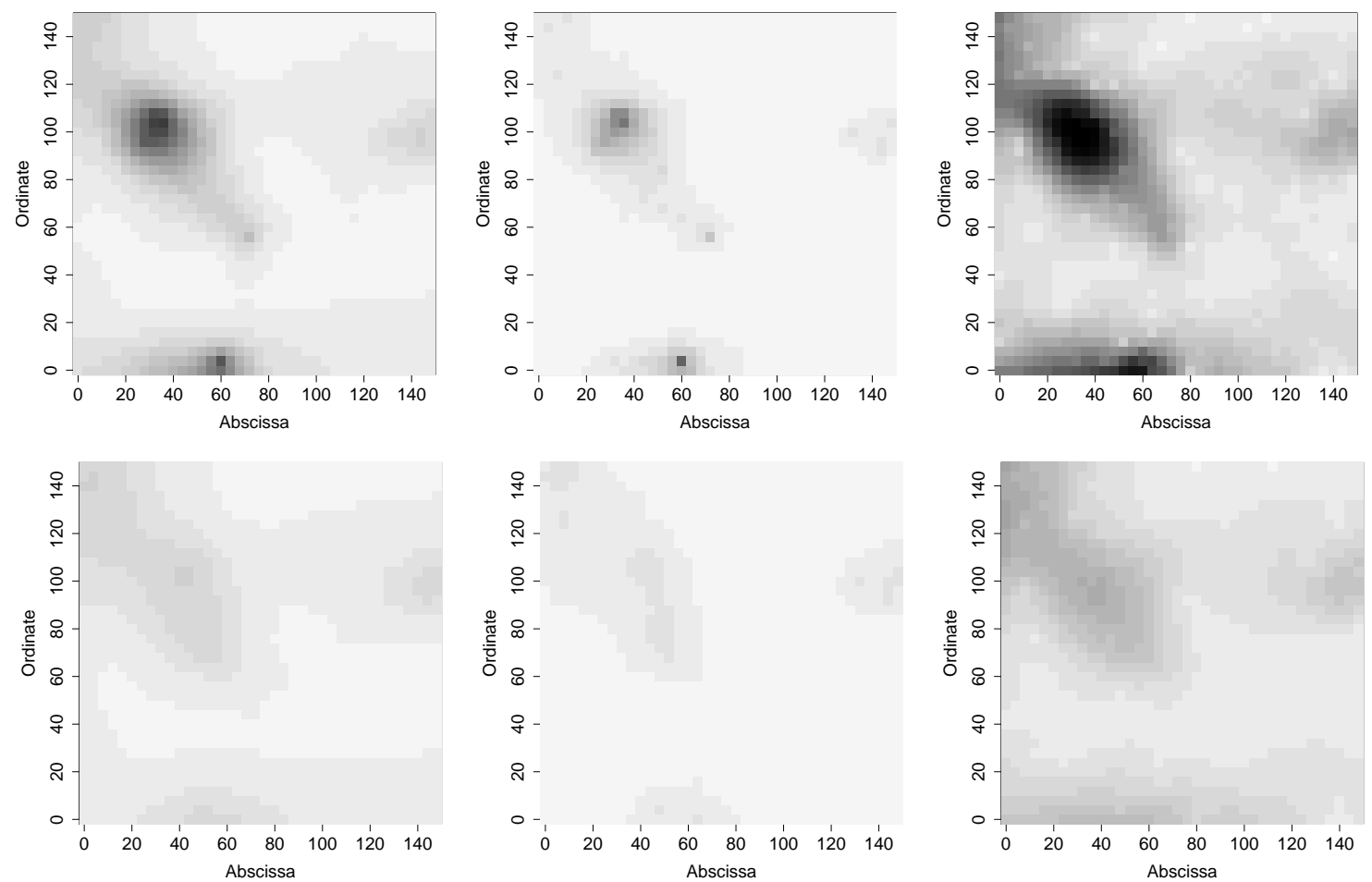

Figure 3: Interpolation for the simulated data. Top: true weed intensity function $\lambda$ and grey scale legend (for all the maps). Second line, from left to right: interpolated posterior median of $\lambda$ and posterior quantiles of order 0.005 and 0.995 using all the data. Third line: same plots obtained when only the abundance data are used. 
Version définitive du manuscrit publiée dans / Final version of the manuscript published in :

Ecological Modelling (2012), Vol. 226, p. 92-98, DOl: 10.1016/j.ecolmodel.2011.10.010,

Journal homepage : www.elsevier.com/locate/ecolmodel
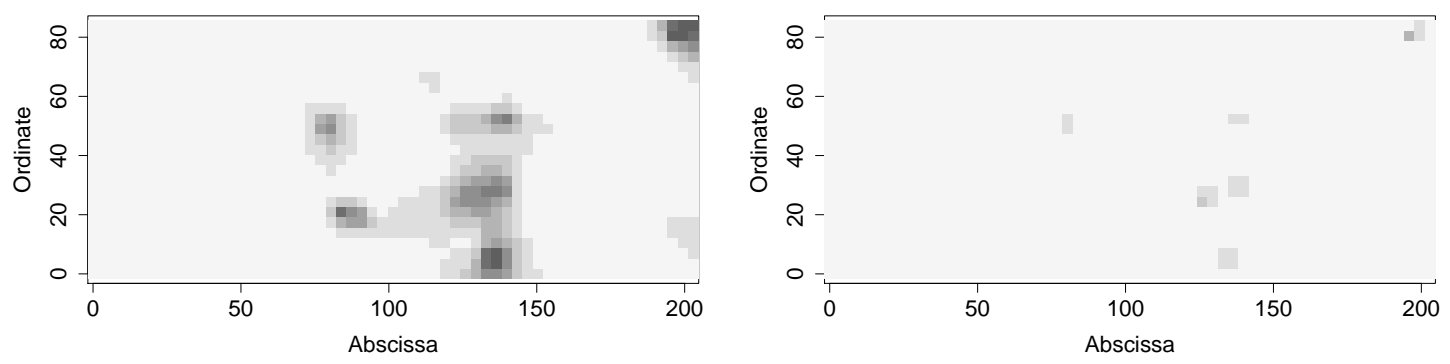

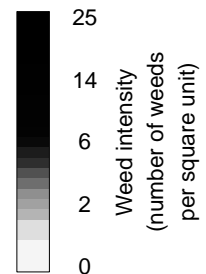

Grey scale

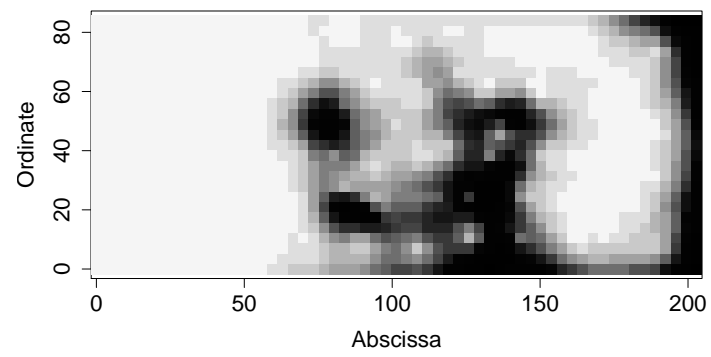

Figure 4: Interpolation for the real data. Left: interpolated posterior median of $\lambda$ and grey scale legend. Right: posterior quantiles of order 0.005 (top) and 0.995 (bottom).

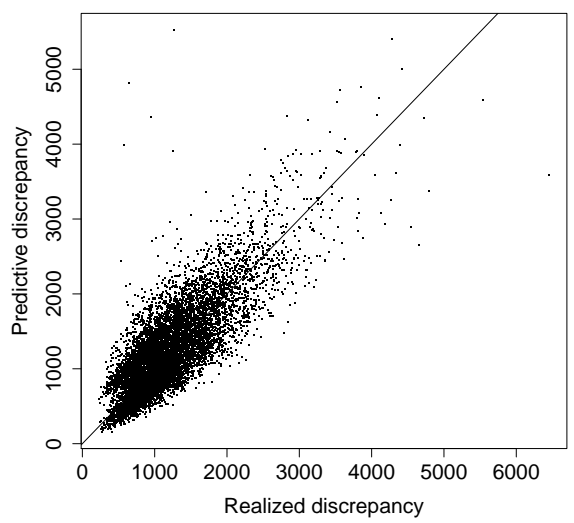

Figure 5: Posterior predictive model check. Scatterplot of predictive versus realized discrepancies under the joint posterior distribution of $\lambda$. The $p$-value is estimated by the proportion of points above the $45^{\circ}$ line. 